\title{
ALTERAÇÕES NÃO PATOLÓGICAS OBSERVADAS NA INSPEÇÃO POST MORTEM EM FRANGOS ABATIDOS INDUSTRIALMENTE NA REGIÃO NORTE DO TOCANTINS.
}

Non-pathological changes observed in post-mortem inspection of industrially slaughtered chickens of the Northern region of Tocantins.

Alteraciones no patológicos observados en la inspección post-mortem de los pollos sacrificados industrialmente de la región Norte de Tocantins.

Leandro Lopes Nepomuceno ${ }^{1}$, Aline Beatriz Schmidt ${ }^{2}$, Fernanda A. Alcântara Conceição ${ }^{3}$, Weber Santos Duarte ${ }^{2}$, Jorge Luís Ferreira ${ }^{* 4}$

${ }^{1}$ Doutorando, Programa de pós-graduação em Ciência Animal, Universidade Federal de Goiás, Goiânia, GO, Brasil.

${ }^{2}$ Acadêmicos do curso de Medicina Veterinária, Universidade Federal do Tocantins, Araguaína-TO, Brasil.

${ }^{3}$ Médica Veterinária, Chefe do setor de Controle e Garantia de Qualidade, Empresa Bonasa Alimentos, Aguiarnopólis, TO, Brasil.

${ }^{4}$ Prof. Adjunto IV. Curso de Medicina Veterinária, Universidade Federal do Tocantins, Araguaína-TO, Brasil.

*Correspondência: Laboratório de Melhoramento Animal - Núcleo de Pesquisa e Extensão em Genética e Melhoramento Animal, Bloco D, sala NAPGEM, Unidade Cimba, Campus de Araguaína, Universidade Federal do Tocantins. Av. Paraguai, esq. c/Rua Uxiramas, s/n Araguaína, Tocantins, Brasil. CEP: 77.824-838. e-mail jorgeuft@gmail.com.

Artigo recebido em 16/01/2017. Aprovado em 22/03/2017. Publicado em 31/03/2017.

\section{RESUMO}

O objetivo desse trabalho foi analisar as principais causas de condenações não patológicas na inspeção post mortem de carcaças de frangos de corte de um abatedouro fiscalizado pelo Serviço de Inspeção Federal (SIF), localizado na região norte do estado do Tocantins. Foi realizado levantamento de dados gerados a partir dos relatórios do SIF, no período de outubro à dezembro/2015, totalizando 1.352 .895 de frangos abatidos. Os dados foram tabulados e agrupados em frequências, mediante o software SAS. Do total de aves abatidas 0,64\% (8.618) foram destinadas à graxaria em virtude da death on arrival (morte na chegada), e 0,33\% (4.432) foram condenadas totalmente por alterações não patológicas (Sangria Inadequada - 77,66\%; Escaldagem Excessiva - 17,38\%; e Outras contaminações - 4,96\%). Foi observado um alto índice de condenações parciais (34.707), sendo os registros de contusões e fraturas de maior frequência $(91,22 \%)$. Grande parte das perdas observadas pode ser atribuída a falta de uma mão de obra técnica especializada e problemas tecnológicos dentro do abatedouro, e maior eficiência no controle e qualidade do produto.

Palavras-chave: condenação, controle de qualidade, lesões.

\section{ABSTRACT}

The objective of this study was to analyze the main causes of non-pathological convictions in the post-mortem inspection of broiler chicken carcasses from a slaughterhouse inspected by the Federal Inspection Service (SIF), located in the northern state of Tocantins. Was held data collection generated from SIF reports, from October to December / 2015, totaling 1,352,895 slaughtered chickens. Data were tabulated and grouped into frequencies by the SAS software. The total number of poultry slaughtered 0.64\% (8,618 Were destined for grease by virtue of 
death on arrival, and $0.33 \%(4,432)$ were totally condemned by non-pathological changes (Sangria Inadequate $77.66 \%$; Scalding Excessive - 17.38\%; and other contaminations - 4.96\%). a high rate of partial convictions were observed (34 707), and the records of bruises and fractures more frequently (91.22\%). Much of the losses observed can be attributed to lack of a hand of specialized technical work and technological problems in the slaughterhouse, And greater efficiency in the control and quality of the product.

Keywords: condemnation, quality control, lesion.

\section{RESUMEN}

El objetivo de este estudio fue analizar las principales causas de las condenas no patológicas en la inspección post mortem de las canales de pollos de engorde de un matadero inspeccionado por el Servicio de Inspección Federal (SIF), ubicado en el norteño estado de Tocantins. Se llevó a cabo la recopilación de datos generados a partir de los informes de SIF, de octubre a diciembre / 2015, por un total de 1,352,895 de pollos sacrificados. Los datos se tabularon y se agrupan en frecuencias por el software SAS. De las aves sacrificadas 0,64\% (8.618) se dirige a la prestación de planta debido a la llegada de la muerte (la muerte a la llegada), y 0,33\% (4.432) fueron totalmente condenado por cambios no patológicos (sangría inadecuada - $77.66 \%$; Escaldado excesivo - 17.38\%; y otras contaminaciones - 4,96\%). Una alta tasa de condenas parciales se observó (34.707), y los registros de las contusiones y fracturas más frecuentes (91,22\%). Gran parte de las pérdidas observadas pueden atribuirse a la falta de mano de obra especializada técnica y problemas tecnológicos en el matadero, y una mayor eficiencia en el control y calidad del producto.

Descriptores: condenación, control de calidad, las lesiones.

\section{INTRODUÇÃO}

A produção brasileira de frango vem se tornando eficiente e de alta produtividade, com um sistema tecnológico avançado visando maior produtividade de proteína animal de origem avícola. O Brasil é o terceiro maior produtor mundial de aves de corte, e lidera o ranque de exportação, contribuindo com renda de 78.392.941 US\$, produzindo um total de 30.653 .340 toneladas de carne de frango industrializada entre julho de 2014 a julho de 2015 (AGROSTAT BRASIL, 2015).

Apesar do grande avanço tecnológico e o aumento da produção de frango, o setor ainda apresenta limitações na produção, como o manejo préabate que acarreta prejuízos a toda a cadeia produtiva (MASCHIO; RASZL, 2012). A qualidade da carcaça está relacionada a maior ou menor índice de condenações no abatedouro, com ausência ou presença de contaminação bacteriana por toxinas e resíduos de produtos químicos e biológicos.
Os sistemas de avaliação da qualidade da carcaça mais comuns baseiam-se em critérios visuais ou estéticos, como conformação, presença de hemorragias e/ ou hematomas, rompimento da pele, ossos quebrados e mutilações. As principais causas de condenação no abatedouro podem ser divididas em sanitárias, manejo e oriunda do processamento durante o abate (CRUZ et al., 2016.).

As condenações por problemas de qualidade das carcaças provocam enormes perdas na produção avícola em todo o país. Qualquer lesão na carcaça é passível de condenação no abatedouro, já que acarretam condenações parciais ou totais durante as atividades da inspeção veterinária oficial no abate (PEREIRA, 2009; TELES et al., 2016).

As condenações podem ter causas patológicas, quanto não patológicas, em ambas, as carcaças podem ser aproveitadas de forma parcial ou totalmente, dependendo do grau da lesão, e critérios de julgamento estabelecidos pelo Serviço de Inspeção Federal (SIF). Segundo a portaria $n^{\circ} 210$ Ministério 
da Agricultura, Pecuária e do Abastecimento que trata do Regulamento Técnico da Inspeção Tecnológica e Higiênicosanitária de carne de aves, as condenações post-mortem podem acontecer nos seguintes casos: processos inflamatórios (artrite, dermatite, salpingite, e colibacilose), tumores, aspecto repugnante, escaldagem excessiva, evisceração retardada, sangria inadequada, magreza, septicemia, caquexia, contaminação, abcesssos e lesões supuradas, aerossaculite, contusão e fraturas, dermatoses, síndrome ascite e doenças especiais (BRASIL, 1998).

A falta de acurácia na linha de produção tem elevado os custos de produção dos frigoríficos. Estas causas de condenação são frequentes no dia-a-dia de um matadouro e também fazem parte do conjunto intitulado "defeitos tecnológicos", isto é, causas de condenações que se originam de um manejo ou processamento tecnológicos inadequado (MACAHYBA et al., 2005).

Desse modo, este trabalho teve como objetivo identificar e quantificar as principais causas de condenações não patológica (total e parcial) na inspeção post mortem de carcaças de frangos de corte de um abatedouro inspecionado pelo Serviço de Inspeção Federal (SIF), localizado na região norte do estado do Tocantins.

\section{MATERIAIS E MÉTODOS}

O trabalho foi desenvolvido mediante levantamento de dados gerados em abatedouro localizado na região norte do estado do Tocantins, em que foram avaliados 1.352 .895 de frangos recebidos entre o período de outubro/2015 à Dezembro/2015, sendo o abate médio de aves em torno de $70 \mathrm{mil}$ aves/dia.

Todos os dados coletados tiveram o acompanhamento do Serviço de Inspeção Federal, com registros de condenações parciais e totais, perfazendo 1.344.277 aves abatidas, que contemplavam diversas causas de condenações de carcaças e vísceras.

Os dados foram tabulados e agrupados em frequências, mediante o software SAS, adotando-se como base o número de aves abatidas durante o presente estudo e as causas de condenação não patológicas.

\section{RESULTADOS E DISCUSSÃO}

Das aves recebidas no abatedouro, 1.344.277 foram encaminhadas a linha de abate, e 8.618 aves $(0,64 \%)$ foram destinadas para graxaria por ter vindo a óbito durante o transporte (death on arrival). $\mathrm{O}$ índice de mortalidade encontrado foi muito alto de acordo com Olivo e Shimokomaki (2006) que recomendaram 0,20\% como valor aceitável de mortalidade para as condições brasileiras. Os mesmos autores relataram valores médios de $0,25 \%$ e verificaram que quanto maior o período de transporte, maior a porcentagem de morte na chegada ao abatedouro.

Um dos fatores que pode ter contribuído para esse índice pode estar relacionado devido às falhas da equipe de apanha durante o carregamento, o transporte, devido às más condições das estradas e o período de transporte. O transporte de aves, em particular, merece atenção especial por corresponder a uma etapa da cadeia produtiva com ligação direta à rentabilidade das empresas (WEEKS, 2014).

Segundo Ferreira et al. (2012), para minimizar as fraturas e as contusões no momento da apanha e transporte, a integração com os produtores devem focar na conscientização de boas práticas de carregamento, transporte, descarregamento e bemestar animal, os quais podem minimizar condenações em etapas posteriores do processo. No presente estudo 
as contusões/fraturas correspondeu a $91,22 \%$ das causas de condenações parciais.

Em análises das condenações de carcaça (tabela 1), foi observado que 4.432 aves $(0,33 \%$ ) foram condenadas totalmente por alterações não patológicas. Dentre esse resultado foi observado que a
Sangria Inadequada (si) apresentou a maior causa de condenação total de carcaça com 77,66\%, seguido da Escaldagem Excessiva (ee) e Outras contaminações totalizando $17,38 \%$ e $4,96 \%$, respectivamente.

Tabela 1. Condenações não patológicas registradas pelo Serviço de Inspeção Federal em frigorifico de aves na região norte do estado do Tocantins, durante o período de outubro a dezembro de 2015.

\begin{tabular}{lcc}
\hline CAUSAS DE CONDENAÇÂO & CONDENAÇÃO & CONDENAÇÃO \\
\hline Sangria Inadequada (si) & TOTAL & PARCIAL \\
Escaldagem Excessiva (ee) & $3.442(77,66 \%)$ & $0(0 \%)$ \\
Outras contaminações (Fecal, Biliar e & $770(17,38 \%)$ & $421(1,21 \%)$ \\
Gástrica) & $220(4,96 \%)$ & $2.534(7,30 \%)$ \\
Evisceração Retardada (er) & $0(0 \%)$ & $92(0,27 \%)$ \\
Contusão/Fratura (cont) & $0(0 \%)$ & $31.660(91,22 \%)$ \\
\hline Total & 4.432 & 34.707 \\
\hline
\end{tabular}

A sangria inadequada foi a maior causa de perda na indústria, esse problema pode ter sido causado pela falta de treinamento dos técnicos responsáveis pela sangria do animal, pois a mesma é feita de forma manual. Os resultados encontrados são superiores aos relatados na literatura (OLIVO; SHIMOKOMAKI, 2006; SOMMER, 2013; OLIVEIRA et al. 2016). Paschoal (2013) avaliando as principais causas de condenações no abate de frangos, observou que a sangria inadequada representou $14,39 \%$ das causas de condenação total, não-patológicas, em um abatedouro localizado na região Noroeste do Paraná.

A escaldagem excessiva e as contaminações (Fecal, Biliar e Gástrica) das carcaças proporcionaram 22,34\% das condenações totais. Esse evento ocorre em grande parte, devido às dificuldades encontradas em ajustar os equipamentos da indústria em relação aos tamanhos irregulares dos frangos (SILVA; PINTO, 2009). A ocorrência de condenação por escaldagem excessiva em matadouros de aves muitas vezes ocorre por paradas de linha do abate, devido a quedas de energia, onde as aves ficam submersas no tanque de escaldagem com água quente, conforme descrito por Maschio \& Raszl (2012).

Maschio \& Raszl (2012) relataram que a contaminação, acontece em grande parte, devido às dificuldades encontradas no ajuste dos equipamentos de evisceração em relação aos tamanhos irregulares dos frangos e por isso é necessária regulagem constante. Estas perdas poderiam ser evitadas com ações dentro do abatedouro, como treinamento dos funcionários e manutenção preventiva dos equipamentos. De acordo com Silva \& Pinto (2009), as oscilações no peso dos frangos comprometem a 
regulagem de máquinas durante o processo de abate, o que implica na condenação de carcaças por contaminação. Assim, faz-se necessário uma seleção de frangos, baseada na morfologia, tipo e tamanho, para o abate com a mínima variação.

Para Pinheiro et al. (2011), tal tipo de situação ocorre devido a presença de conteúdo intestinal ou sais biliares tanto pelo rompimento do trato intestinal ou a vesícula biliar durante o processo de evisceração.

Dentre as condenações parciais, observou-se que as fraturas e contusões foram a principal causa $(91,22 \%)$. Embora haja um aproveitamento parcial do produto, através de seu beneficiamento, através de cortes ou embutidos, existe uma perda econômica muito grande ao sistema (produtor-indústriaqualidade). Os fatores que podem influenciar nesse tipo de condenação estão ligados ao manejo préabate, destacando-se o método de apanha, o tempo de transporte, tempo de espera, tipos de caixas de transporte, densidade por gaiola, período de apanha, idade, sexo e temperatura de transporte (SOMMER, 2013).

Oliveira et al. (2016), em estudo de identificação das principais causas de condenação de aves, através do sistema de informações gerenciais do SIF, no período de 2006 a 2011, no Brasil, verificaram que contusão e lesões traumáticas contribuíram com 2,17\% para região norte do Brasil. Os mesmos também relatam que esta causa conjuntamente às contaminações são as principais causas de condenação nos matadouros/frigoríficos no Brasil.

Os dados não patológicos decorrentes do abate são bons indicadores para a alteração das práticas de manejo adotadas pelas granjas de modo a diminuir as perdas econômicas. Portanto, fica evidente que os serviços de inspeção oficial no matadouro-frigorífico, além de garantir a qualidade da carne e da saúde dos consumidores, também fornece subsídios para a Defesa Sanitária Animal

Este trabalho possibilitou adquirir um olhar mais crítico sobre a produção de aves de corte, sendo importante a devida atenção ao manejo e sanidade durante todo o processo de produção, na tentativa de reduzir as perdas econômicas e manter os bons padrões de qualidade do produto, para proteger os consumidores e a sua saúde sendo de responsabilidade do setor de qualidade notificar esses pontos críticos de controle e falhas dentro da indústria.

Assim, melhorias nas condições de bem-estar e redução de estresse nos animais, no transporte e manejo pré-abate, bem como treinamento e pessoal capacitado na indústria, podem minimizar a ocorrência de condenações não patológicas no abate de aves.

\section{CONCLUSÃO}

Grande parte das perdas observadas pode ser atribuída a falta de mão-de-obra especializada e problemas tecnológicos nas linhas de processamento do abatedouro. As causas mais prevalentes, dentre as contaminações totais foram Sangria Inadequada (si), Escaldagem Excessiva (ee) e contaminações (Fecal, Biliar e Gástrica).

Todos os autores declararam não haver qualquer potencial conflito de interesses referente a este artigo.

\section{REFERÊNCIAS}

AGROSTAT - Produção de carne de aves no Brasil. AgroStat Brasil, 2015. Disponível em <http://sistemasweb.agricultura.gov.br/pages/AGROS TAT.html>. Acesso em: 26 nov. 2015.

CRUZ, A. P., TELES, M. M., OLIVEIRA, S. L. C. L., FERREIRA, F. C., CORREIA, F. I. P., MOURA, R. R. Condenações não patológicas no abate de frangos em estabelecimentos sob inspeção estadual 
no Ceará. Revista de Educação Continuada em Medicina Veterinária e Zootecnia, v. 14, n. 2, p. 75-75, 2016.

FERREIRA, T.Z.; SESTERHENN, R.; KINDLEIN, L. Perdas econômicas das principais causas de condenações de carcaças de frangos de corte em matadouros-frigoríficos sob inspeção federal no Rio Grande do Sul, Brasil. Acta Scientiae Veterinariae, v.40, n.1, p.1021-1026, 2012.

MACAHYBA, R. B., MANO, S. B., de FREITAS, M. Q., BAPTISTA, R. F. Condenações post mortem em perus (Meleagris gallopavo) criados na região oeste catarinense e abatidos sob Inspeção Federal. Revista Brasileira de Ciência Veterinária, v. 12, n. 1-3, 2005.

BRASIL, Ministério da Agricultura, Pecuária e do Abastecimento - MAPA. Portaria no 210 de 10 de novembro de 1998: Aprova o Regulamento técnico da inspeção tecnológica e higiênicosanitária de carne de aves. Diário Oficial da República Federativa do Brasil, Brasília, DF, 1998. 38 p.

MASCHIO, Marina Manfroi; RASZL, Simone Moraes. Impacto financeiro das condenações postmortem parciais e totais em uma empresa de abate de frango. Revista E-Tech: Tecnologias para Competitividade Industrial, p. 26-38, 2012.

OLIVEIRA, A. A., ANDRADE, M. A., ARMENDARIS, P. M., BUENO, P. H. S. Principais causas de condenação ao abate de aves em matadouros frigoríficos registrados no serviço brasileiro de inspeção federal entre 2006 e 2011. Ciência Animal Brasileira, v.17, n.1, p.79-89, 2016.

OLIVO, R.; SHIMOKOMAKI, M. Carne PSE em aves. In: SHIMOKOMAKI, M. et al. (Ed.). Atualidades em ciência e tecnologia de carnes. São Paulo: Varela, p. 95-103, 2006.

PASCHOAL, E. C., OTUTUMI, L. K., SILVEIRA, A. P. Principais causas de condenações no abate de frangos de corte de um abatedouro localizado na região noroeste do Paraná, Brasil. Arquivos de
Ciências Veterinárias e Zoologia da UNIPAR, v.15, n.2, p.93-97, 2013.

PEREIRA, S.L.S. Condenações no abate de frangos de corte. 2009. 41p. Monografia - (Especialização) Universidade Castelo Branco UCB. Pós-graduação em Higiene e Inspeçãode Produtos de Origem Animal e Vigilância Sanitária em Alimentos. 38p., Campinas, 2009.

PINHEIRO, R.E.E.; COSTA FILHO, J.A. A.; CARDOSO FILHO, F.C.; KLEIN JÚNIOR, M.H.; FERREIRA, L.C.R.P.; FURTADO, J.A.L. Condenações não patológicas no abate de frangos em Teresina, PI. Higiene Alimentar, v. 25, p. 525527,2011

SILVA, V. A. M.; PINTO, A. T. Levantamento das condenações de abate de frango e determinação das causas mais prevalentes em um frigorífico de Santa Catarina. In: Congresso Brasileiro de Avicultura, Anais... Porto Alegre: UFRGS. 2009.

SOMMER Jandréia. Relatório De Estágio Curricular Supervisionado Em Medicina Veterinária. Universidade Regional do Noroeste do Estado do Rio Grande Do Sul Departamento de Estudos Agrários Curso de Medicina Veterinária. Ijuí, RS, Brasil, 2013. Disponível em: http:// bibliodigital.unijui.edu.br. Acessado em: 23 de janeiro de 2016.

STATISTICAL ANALYSIS SYSTEMS -SAS. User's guide. Version 8.2.1 ed.Cary: 956p. 2002.

TELES, M. M., OLIVEIRA, S. L. C. L., VIEIRA, S. F., PEREIRA, J. A., CRUZ, A. P. Principais causas de condenações totais de carcaças de frangos de corte em matadouros--frigoríficos sob inspeção estadual no Ceará. Revista de Educação Continuada em Medicina Veterinária e Zootecnia, v. 14, n. 2, p. 75-75, 2016.

WEEKS, C.A. Poultry handling and transport. In: GRANDIN, T. (Ed.) Livestock handling and transport. 4ed. Colorado: Cabi, p. 174-192, 2014. 